\title{
Growth velocity and weight gain in prepubertal asthmatic children
}

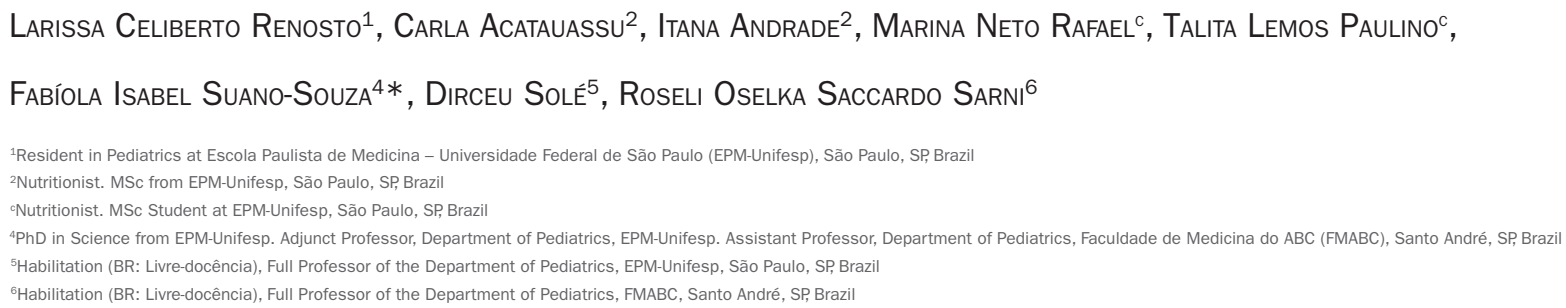

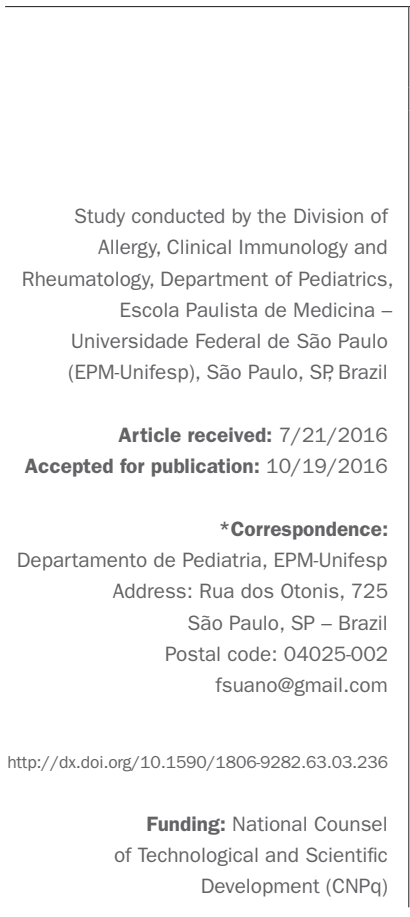

\section{SUMmARY}

Objective: To evaluate the stature growth rate (GR) and the weight gain of prepubertal asthmatic children.

Method: A retrospective cohort study evaluating medical records of 85 children diagnosed with asthma, aged less than 9 years, of both sexes, with at least one year of follow-up in the allergy outpatient clinic. The data on the disease, weights and heights were collected through a standardized questionnaire on two occasions, with an interval of one year. The curves proposed by Tanner were applied for the analysis of the GR, and the Z-score of the GR (ZGR) was calculated.

Results: Excess weight (risk for overweight, overweight and obesity) was observed in $31.8 \%(27 / 85)$ of the patients, but there was no association with the severity of asthma. Low GR (ZGR <-2) was found in 13.9\% (11/79) of patients, most frequently among children with moderate/severe persistent asthma compared to persistent mild and intermittent forms ( $7 / 11-63.6 \%$ vs. $21 / 68$ - 30.2\%, respectively, $\mathrm{p}=0.047)$. Use of steroids (dose, type and time of use) was not associated with GR.

Conclusion: GR was most affected in children with moderate/severe asthma.

Keywords: asthma, children, nutritional status, corticosteroids, weight-height.

\section{INTRODUCTION}

Currently, it is estimated that about 300 million people have asthma worldwide. Adequate treatment allows for satisfactory control of symptoms and improvement of the quality of life of affected individuals. ${ }^{1}$

Inhaled corticosteroids (IC) are the main medications currently used in the maintenance treatment of patients with asthma, because they reduce the frequency and severity of attacks. Its use is associated with fewer hospitalizations and care in emergency services, better quality of life and improved lung function. ${ }^{2}$ The goal of treatment is control of the disease and remission of exacerbations with the lowest possible doses. ${ }^{1}$

Systemic adverse events are described with varying intensity and dependent on the drug, dose and time of use, including: loss of bone mass, inhibition of the hypothalamic pituitary adrenal axis and growth deficit (with no change in growth cartilage). ${ }^{c}$ However, there is debate as to the damage of growth in asthmatic children being more intense when the disease is not controlled, and that even with the use of IC the benefits related to disease control overlap with possible adverse events. ${ }^{1}$

In Brazil, in the pediatric population in general, the prevalence of stature impairment has been significantly reduced in the last decades. Nevertheless, it is still greater than observed in developed countries. ${ }^{4}$ It is therefore important to evaluate the growth profile of asthmatic children in our country, using the currently recommended treatment protocols.

The goal of our study was to evaluate the stature growth rate (GR) and the weight gain of prepubertal asthmatic children.

\section{Method}

In a retrospective cohort study, we evaluated the charts of children diagnosed with asthma according to the Global Initiative for Asthma (GINA). ${ }^{5}$ The patients were sensitized to aeroallergens, aged over 2 and under 9 years, 
of both sexes, enrolled and regularly monitored for at least one year in the outpatient clinic of the Division of Allergy, Clinical Immunology and Rheumatology of the Pediatrics Department of Escola Paulista de Medicina da Universidade Federal de São Paulo (EPM-Unifesp).

The study was approved by the Research Ethics Committee of EPM-Unifesp (No. 65814/2012). Patients with non-allergic asthma (lack of sensitization to aeroallergens) and other chronic non-allergic diseases (endocrinopathies, autoimmune diseases, immunodeficiencies, genetic syndromes) were excluded.

Data were collected from electronic medical records available at EPM-Unifesp and all consultations whose International Code of Diseases (ICD) was related to asthma (J45) were assessed.

After evaluation of the medical records and application of the inclusion and exclusion criteria, 85 patients were included. Patient data were collected from these 85 medical charts through a standardized questionnaire containing: identification data; personal, feeding (total breastfeeding duration) and morbid (hospitalizations, previous and current diseases) history; results of hypersensitivity tests; presence of domestic animals and smokers at home; other associated allergic diseases; classification and control of asthma (GINA); medication used (IC and oral) and respective dosages; maximum expiratory flow rate; weight and height with a maximum interval of 6 months ( \pm 2 months).

Considering that different types of IC were used, the doses received were converted to beclomethasone as a reference. ${ }^{5}$ In addition, the IC propellant was taken into account: $400 \mathrm{mcg}$ of inhaled budesonide powder corresponded to $250 \mathrm{mcg}$ of beclomethasone HFA spray; $250 \mathrm{mcg}$ of fluticasone or mometasone HFA spray amounted to $500 \mathrm{mcg}$ of beclomethasone HFA spray. Prednisone was the oral corticosteroid (OC) most commonly used by patients. Based on dosage calculation of beclomethasone/day, doses equal to or greater than $400 \mathrm{mcg} /$ day, between 200 and $400 \mathrm{mcg} /$ day, and below $200 \mathrm{mcg} /$ day were considered, respectively, as high, medium and low exposure. ${ }^{5}$

Weight and height data were used to calculate a Z-score of body mass index for age (Z-BMI) and height for age $(\mathrm{H} / \mathrm{A})$, using WHO Anthro Plus ${ }^{\circledR}$ software, which were compared to World Health Organization (WHO) reference values (2006 and 2007). ${ }^{6}$ The curves proposed by Tanner were applied for the analysis of the GR. ${ }^{7}$

SPSS 19.0 package was used for statistical analysis, and continuous variables were tested for their normality by means of the Kolmogorov-Smirnov test, being compared by the Mann-Whitney test (non-parametric data) and Student's $\mathrm{t}$-test (parametric) for independent variables. T-Paired test and Freedman's test were applied to compare the nutritional status at different times, for the parametric and non-parametric data, respectively. The level of significance was 5\%.

\section{ResULTS}

In the studied sample, males predominated (60/85 [70.6\%]) and the median age was 5.5 years (2.1-8.4) (Table 1). The most prevalent nutritional disorders were risk for overweight $15 / 85$ (17.7\%), overweight $5 / 85$ (5.9\%), and obesity $7 / 85$ (8.2\%), while three children had a short stature $3 / 85$ (3.5\%).

\section{TABLE 1 Characteristics of the population.}

\begin{tabular}{|c|c|c|}
\hline Variable & & Values \\
\hline \multicolumn{3}{|l|}{ General characteristics } \\
\hline Gender $(n=85)$ & Male:Female & $57: 28^{a}$ \\
\hline Age at first evaluation $(n=85)$ & Years & $5.5(2.1-8.4)^{\mathrm{b}}$ \\
\hline Age at second evaluation $(n=85)$ & Years & $5.9(2.6-8.7)^{\mathrm{b}}$ \\
\hline Age at third evaluation $(n=85)$ & Years & $6.5(3.2-9.7)^{\mathrm{b}}$ \\
\hline Pets $(n=85)$ & Yes & $27(31.8 \%)^{c}$ \\
\hline Smokers $(n=85)$ & Yes & $37(43.5 \%)^{c}$ \\
\hline $\begin{array}{l}\text { Total breastfeeding } \\
\text { duration }(n=72)\end{array}$ & $<6$ months & $62(68.9 \%)^{c}$ \\
\hline \multicolumn{3}{|l|}{ Anthropometry } \\
\hline \multirow[t]{7}{*}{ Nutritional status $(\mathrm{n}=85)$} & $\begin{array}{l}\text { Low stature and } \\
\text { malnutrition }\end{array}$ & $1(1.2 \%)^{c}$ \\
\hline & $\begin{array}{l}\text { Low stature and } \\
\text { normal weight }\end{array}$ & $2(2.4 \%)^{c}$ \\
\hline & Malnutrition & $1(1.2 \%)^{c}$ \\
\hline & Normal weight & $54(63.5 \%)^{c}$ \\
\hline & Risk for overweight & $15(17.7 \%)^{c}$ \\
\hline & Overweight & $5(5.9 \%)^{c}$ \\
\hline & Obesity & $7(8.2 \%)^{c}$ \\
\hline Growth rate $(n=85)$ & Z score HA / year & $-0.3(-6.2 ; 5.2)^{b}$ \\
\hline Weight gain rate $(n=85)$ & Z score BMI / year & $0.03(-3.5 ; 1.4)^{\mathrm{b}}$ \\
\hline \multicolumn{3}{|l|}{ Asthma characteristics } \\
\hline \multirow[t]{3}{*}{ Asthma classification $(\mathrm{n}=85)$} & Intermittent & $20(23.5 \%)^{c}$ \\
\hline & Persistent mild & $32(37.6 \%)^{c}$ \\
\hline & $\begin{array}{l}\text { Persistent } \\
\text { moderate }\end{array}$ & $31(36.5 \%)^{c}$ \\
\hline \multirow{2}{*}{$\begin{array}{l}\text { Associated atopic } \\
\text { diseases }(n=85)\end{array}$} & Rhinitis & $82(96.5 \%)^{c}$ \\
\hline & Dermatitis & $29(34.1 \%)^{c}$ \\
\hline Attacks in the period between & Yes & $37(43.5 \%)^{c}$ \\
\hline medical appointments $(\mathrm{n}=85)$ & Median (min-max) & $1.0(0.0-3.0)^{\mathrm{b}}$ \\
\hline School absences due to asthma & Yes & $41(45.5 \%)^{c}$ \\
\hline attacks $(n=85)$ & $\begin{array}{l}\text { Median in days } \\
(\min -\max )\end{array}$ & $1.5(0.0-12.0)^{b}$ \\
\hline
\end{tabular}

Absolute value

Median (minimum-maximum)

'Number and percentage.

$\mathrm{HA}$ : height for age; BMI: body mass index. 
Asthma was classified as intermittent in 20/85 (23.5\%), persistent mild in 32/85 (37.6\%) and persistent moderate/ severe in $31 / 85$ (36.5\%) of the evaluated patients. Allergic rhinitis and atopic dermatitis, concomitant to asthma, were described in $82 / 85$ (96.5\%) and 29/85 (36.4\%) of the children, respectively.

Asthma severity was not associated with the presence of other atopic diseases, overweight or obesity, gender, duration of breastfeeding, presence of pets or smokers at home (data not shown).

Low GR was observed in 11/79 (13.9\%) of the children and, of all variables (Table 2), this was associated only with persistent moderate/severe asthma compared with persistent mild and intermittent forms $(7 / 11-63.6 \%$ vs. $21 / 68-30.2 \% ; p=0.047)$ (Chart 1).

Use of IC and OC was observed in 60/79 (75.9\%) and $41 / 79$ (51.8\%) of the studied children, respectively. The frequency of $\mathrm{OC}$ use was low, on average once a year. Neither the use nor the dose of IC (Table 3) or OC was associated with worse GR in the children studied.

\section{Discussion}

The present study showed an association between low GR and asthma severity, regardless of IC treatment. Budesonide inhalation was the most commonly used IC, being available in the public health system and in the high-cost asthma medication program.

Similar to the results observed here, a longitudinal study involving 315 children and adolescents with asthma and 82 controls, aged 7 to 14 years, showed height impairment in patients with more severe disease and over 10 years of age, especially in the group aged 14 years. ${ }^{8}$ Solé et al., in turn, in a study performed in the city of São Paulo, compared 397 patients with allergic diseases (asthma, rhinitis, urticaria and atopic dermatitis), aged between 8 months and 14 years, with 1,723 normal individuals, matched for age but of a higher socioeconomic profile, and they did not find any association between growth deficit and asthma severity. ${ }^{9}$

Several situations could determine impaired growth when associated with asthma per se: early onset, disease duration and severity, chest deformity, hypoxemia, changes in pulmonary function and increased metabolic demands due to increased ventilatory effort,$^{10}$ in addition to low socioeconomic conditions, ${ }^{11}$ sedentary behavior ${ }^{12}$ and sleep disorders. ${ }^{1 c}$ Changes in growth hormone secretion, previously described, have not been proven in recent studies..$^{14,15}$ Pubertal delay and reversible deceleration of stature growth in the prepubertal period have also been described. ${ }^{16}$

There is no consensus in the literature about growth retardation associated with the use of IC. It should be noted that there are few clinical trials evaluating GR during IC use and that it is difficult to compare these studies in view of the different treatments employed. ${ }^{17}$

A recent systematic review and meta-analysis assessed the impact of different types and doses of IC (beclomethasone, budesonide, ciclesonide, fluticasone and mometasone; alone or combined with long-acting beta-agonists)

TABLE 2 Comparison of the variables studied in children regarding growth rate (GR).

\begin{tabular}{lllll} 
Variable & & ZGR $\leq \mathbf{- 2 . 0}$ & ZGR $>-\mathbf{2 . 0}$ \\
(n=68) & P-value* & \\
\hline Sex & Male & $7(63.4 \%)$ & $45(66.2 \%)$ & 0.560 \\
\hline Age & $<5$ years & $3(27.2 \%)$ & $32(47.0 \%)$ & 0.329 \\
\hline Attacks & Yes & $3(27.2 \%)$ & $36(52.9 \%)$ & 0.193 \\
\hline Nutritional status & Normal weight vs. excess weight & $0(0.0 \%)$ & $7(10.0 \%)$ & 0.585 \\
\hline Pets & Yes & $4(36.4 \%)$ & $21(31.0 \%)$ & 0.735 \\
\hline Smokers at home & Yes & $4(36.4 \%)$ & $31(45.6 \%)$ & 0.746 \\
\hline Breastfeeding & $<6$ months vs. $>6$ months & $4(36.4 \%)$ & $23(33.8 \%)$ & 0.560 \\
\hline Presence of rhinitis & Yes & $11(100 \%)$ & $65(65.0 \%)$ & 0.634 \\
\hline Presence of dermatitis & Yes & $4(36.4 \%)$ & $24(35.3 \%)$ & 0.597 \\
\hline Type of asthma & Pers.mod vs. Interm + Pers.mild & $7(63.4 \%)$ & $21(31.0 \%)$ & 0.047 \\
\hline Inhaled CS & Yes & $9(81.8 \%)$ & $51(75.0 \%)$ & 0.472 \\
\hline Intranasal CS & Yes & $11(100 \%)$ & $64(94.1 \%)$ & 0.542 \\
\hline Prednisolone & Yes & $4(36.4 \%)$ & $37(54.4 \%)$ & 0.338 \\
\hline Inhaled CS & $>400$ mg/day & $6(54.5 \%)$ & $25(36.7 \%)$ & 0.474 \\
\hline
\end{tabular}

* Level of significance of the Chi-square test or Fisher's exact test.

Pers.mod vs. Interm + Pers.mild: persistent moderate vs. intermittent and persistent mild asthma; ZGR: Z score for growth rate; CS: corticosteroid. 


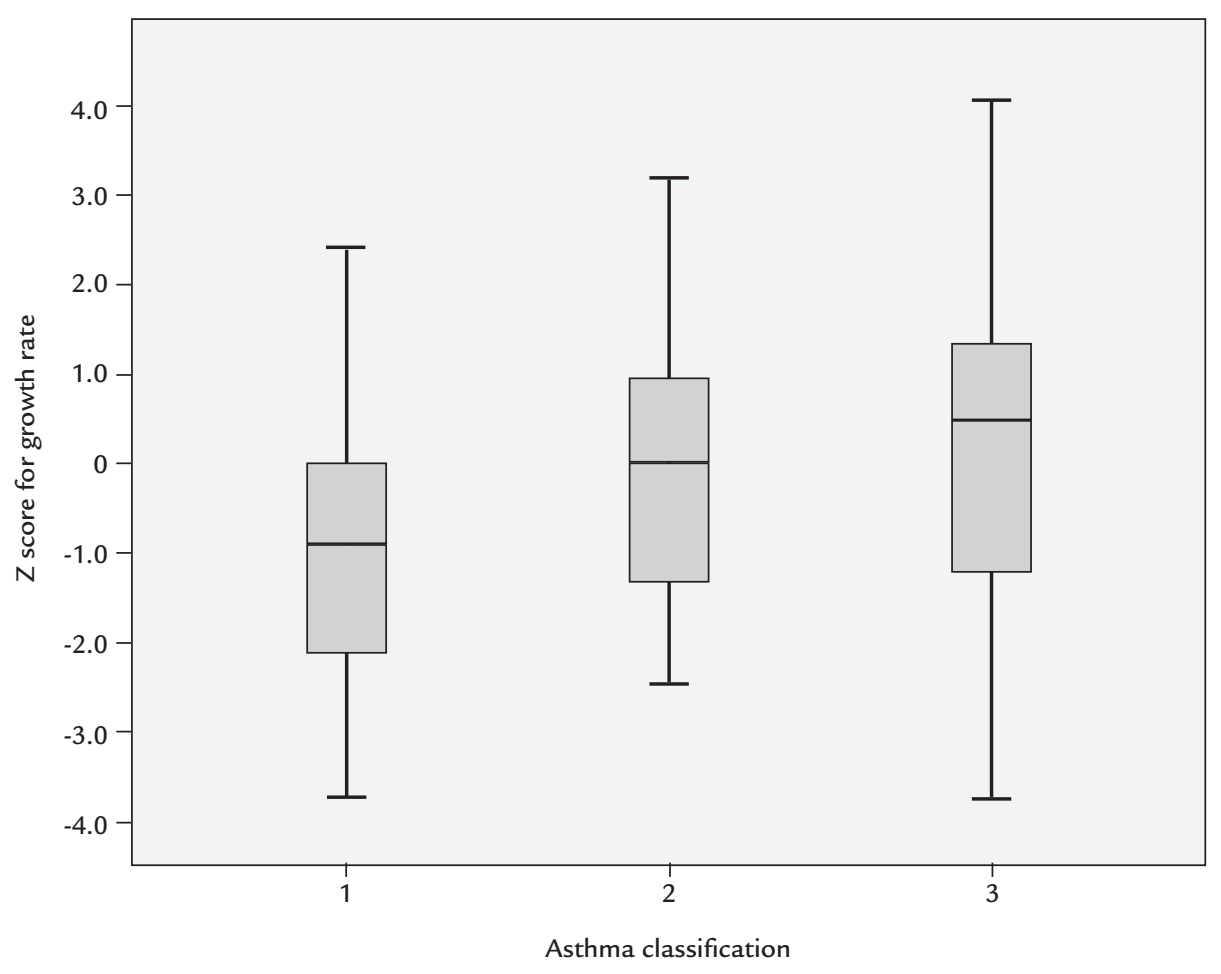

CHART 1 Comparison of growth rate Z score according to asthma severity.

1: persistent moderate; 2: persistent mild asthma; 3 : intermittent asthma.

ANOVA test $(p=0.023)$

Tukey's range test: 1 vs. $3(-1.31 ; p=0.038)$.

\section{TABLE 3 Inhaled corticosteroid (IC) in patients with asthma, stratified according to growth rate (GR).}

\begin{tabular}{|c|c|c|c|c|c|}
\hline \multicolumn{2}{|c|}{ Z score for GR } & \multirow{2}{*}{$\begin{array}{l}\text { Total IC dose (mg/year) } \\
157,500.0\end{array}$} & \multirow{2}{*}{$\begin{array}{l}\text { Duration of IC use (days) } \\
360.0\end{array}$} & \multirow{2}{*}{$\begin{array}{l}\text { IC dose (mg/day) } \\
458.3\end{array}$} & \multirow{2}{*}{$\begin{array}{l}\text { Duration of IC use (days) } \\
12.0\end{array}$} \\
\hline$\leq-2.0$ & Median & & & & \\
\hline & Minimum & $22,500.0$ & 90.0 & 195.6 & 3.0 \\
\hline & Maximum & $315,000.0$ & 360.0 & 875.0 & 12.0 \\
\hline & $\mathrm{N}$ & 9 & 9 & 9 & 9 \\
\hline \multirow[t]{4}{*}{$>-2.0$} & Median & $123,750.0$ & 345.0 & 400.0 & 11.5 \\
\hline & Minimum & $11,250.0$ & 45.0 & 109.1 & 1.5 \\
\hline & Maximum & $510,000.0$ & 360.0 & $1,625.0$ & 12.0 \\
\hline & $\mathrm{N}$ & 51 & 51 & 51 & 51 \\
\hline \multirow[t]{5}{*}{ Total } & Median & $131,250.0$ & 352.5 & 407.3 & 11.7 \\
\hline & Minimum & $11,250.0$ & 45.0 & 109.1 & 1.5 \\
\hline & Maximum & $510,000.0$ & 360.0 & $1,625.0$ & 12.0 \\
\hline & $\mathrm{N}$ & 60 & 60 & 60 & 60 \\
\hline & $\mathrm{p}$-value & 0.413 & 0.236 & 0.647 & 0.236 \\
\hline
\end{tabular}

*Mann-Whitney test's significance level. 
on GR of asthmatic children revealing a modest but significant negative effect of moderate doses (100 to $200 \mathrm{mcg} /$ day of beclomethasone HFA) compared with low doses (50 to $100 \mathrm{mcg} /$ day of beclomethasone HFA). There was no difference among ciclesonide, fluticasone and mometasone. The authors pointed out that in $86 \%$ of eligible clinical trials, there were no data on GR, or the information was incomplete. In addition, they emphasize the importance of including GR monitoring in future studies and reinforce the recommendation of lower IC doses in children following disease control and during their maintenance treatment. ${ }^{2}$

The absence of an association between GR impairment and IC in our study can be explained by the short interval between the two evaluations. Similar results were previously described by Singh et al. in preschoolers. ${ }^{18}$ A review points to different results depending on the duration of exposure to treatment and the anthropometric assessments performed..$^{19}$ Other hypotheses to explain such findings may be low adherence to the treatment prescribed, reduced numbers of patients with severe forms of asthma and individual variability due to genetic characteristics. A study involving children with persistent asthma aged between 5 and 14 years showed low adhesion rates to beclomethasone propionate (measured by electronic monitor), corresponding to $31.2 \%$ after 12 months of treatment. ${ }^{20}$

A recent meta-analysis showed a small, but significant, difference $(-0.2 \mathrm{~cm} /$ year) in GR over 12 months in the group treated with a high IC dose schedule. Studies with a duration of more than one year and good methodological quality are scarce. We emphasize the importance and necessity of future studies with longer observation intervals. ${ }^{21}$

Another concern is the persistence of reduction in the adult's final height due to the use of IC as a child. A study that included 173,034 Swedish military recruits aged 18 years (8,531 asthmatics) showed a discrete but significant difference in height between asthmatics and normal controls, with a negative correlation between height and asthma severity. ${ }^{22}$

Adequate monitoring of anthropometric parameters and the identification of groups at risk for poor growth, especially in cases of severe asthma, should be treatment goals, favoring a better quality of life for the patients.

Although in these studies the comparison between the different drugs is based on dose equivalence compared to beclomethasone, we cannot disregard the bioavailability of these different drugs. Among ICs, beclomethasone is more bioavailable, i.e., there is a large amount of circulating drug after the first passage through the liver, ${ }^{2 c}$ unlike fluticasone, mometasone and ciclesonide. When these drugs are used in high doses, the adverse events occur in a linear way, as with beclomethasone.

Although indicated as safe, patients on long-term IC treatment, regardless of dose and drug, should be monitored for early diagnosis of possible adverse effects.

There are few studies evaluating weight gain in asthmatic children and IC. What is known is that being overweight is associated with more severe asthma and more attacks. There seem to be several factors involved in this process. The most important are insulin resistance and the inflammatory state related to the increase of adipose tissue. ${ }^{24}$ The association between obesity and asthma would potentiate the inflammatory state via TH1 and TH2 pathways. IC use is not related to greater weight gain in asthmatic children. ${ }^{25}$

\section{Conclusion}

There is a greater impairment of the GR in asthmatic children with more severe forms (moderate/severe asth$\mathrm{ma}$ ). The presence of associated rhinitis in $98.9 \%$ of the sample seems to suggest an important connection between the two allergic diseases (asthma and rhinitis). There was no association of GR with nutritional status, smoking, other allergic diseases, presence of pets at home, breastfeeding or use of steroids. The type, dose or time of use of corticosteroids did not negatively influence the GR of the asthmatic children analyzed in the study's follow-up period.

The importance of outpatient follow-up for children with asthma should be emphasized, as it can positively influence the quality of life of these patients, since the control performed with inhalers seems to lead to a decrease in asthma attacks, preventing excessive and harmful exposure to oral steroids (systemic).

In addition, nutritional monitoring of asthmatic children is also a relevant factor for their quality of life. Since asthma, short stature and excess weight are chronic diseases, it is believed that the association of these conditions increases the risk of chronic non-communicable diseases in the future. Therefore, it would be interesting to develop strategies with combined protocols for investigation and treatment, aiming to improve these conditions early and to reduce long-term repercussions. New perspectives to deepen the study of nutritional disorders (excesses and deficiencies) in asthmatic children would thus be explored.

\section{Conflict of InTERest}

The authors declare no conflict of interest. 


\section{Resumo}

Velocidade de crescimento e ganho de peso em crianças pré-púberes asmáticas

Objetivo: Avaliar a velocidade de crescimento estatural e o ganho de peso de crianças asmáticas pré-púberes.

Método: Estudo de coorte retrospectiva que avaliou 85 prontuários de crianças com diagnóstico de asma, menores de 9 anos, de ambos os sexos, com no mínimo um ano de acompanhamento no ambulatório de alergia. Os dados relativos à doença, aos pesos e às alturas foram coletados por meio de questionário padronizado em dois momentos com intervalo de um ano. Para análise da velocidade de crescimento (VC), foram empregadas as curvas propostas por Tanner e realizado o cálculo do escore $\mathrm{Z}$ da VC (ZVC). Resultados: $O$ excesso de peso (risco para sobrepeso, sobrepeso e obesidade) foi observado em 31,8\% (27/85) dos pacientes, mas sem associação com a gravidade da asma. Velocidade de crescimento baixa $(Z \mathrm{VC}<-2)$ foi encontrada em 13,9\% (11/79) dos pacientes, com maior frequência entre as crianças com asma persistente mode$\mathrm{rada} /$ grave em relação às formas persistente leve e intermitente $(7 / 11$ - 63,6\% vs. $21 / 68$ - 30,2\%, respectivamente; $\mathrm{p}=0,047)$. O uso de corticosteroides (dose, tipo e tempo de uso) não mostrou associação com a VC.

Conclusão: Foi constatado um maior comprometimento da VC em crianças com asma moderada/grave.

Palavras-chave: asma, crianças, estado nutricional, corticosteroides, peso-estatura.

\section{REFERENCES}

1. Boulet LP, FitzGerald JM, Levy ML, Cruz AA, Pedersen S, Haahtela T, et al A guide to the translation of the Global Initiative for Asthma (GINA) strategy into improved care. Eur Respir J. 2012; 39(5):1220-9.

2. Pruteanu AI, Chauhan BF, Zhang L, Prietsch SO, Ducharme FM. Inhaled corticosteroids in children with persistent asthma: dose-response effects on growth. Cochrane Database Syst Rev. 2014; (7):CD009878.

3. Pandya D, Puttanna A, Balagopal V. Systemic effects of inhaled corticosteroids: an overview. Open Respir Med J. 2014; 8:59-65.

4. de Onis M, Blössner M, Borghi E. Prevalence and trends of stunting among pre-school children, 1990-2020. Public Health Nutr. 2012; 15(1):142-8.
5. Global Initiative for Asthma. Global Strategy for Asthma Management and Prevention, 2014. [cited 2015 Feb 29]. Available from: http://www ginasthma.org/.

6. de Onis M, Onyango AW, Borghi E, Siyam A, Nishida C, Siekmann J Development of a WHO growth reference for school-aged children and adolescents. Bull World Health Organ. 2007; 85(9):660-7.

7. Tanner JM, Whitehouse RH, Takaishi M. Standards from birth to maturity for height, weight, height velocity and weight velocity: British children, 1965 I Arch Dis Child. 1966; 41(219):454-71.

8. Mcnicol KN, Macnicol KN, Williams HB. Spectrum of asthma in children I. Clinical and physiological components. Br Med J. 1973; 4(5883):7-11.

9. Solé D, Castro AM, Naspitz CK. Growth in allergic children. J Asthma. 1989; 26(4):217-21.

10. Santuz P, Baraldi E, Filippone M, Zacchello F. Exercise performance in children with asthma: is it different from that of healthy controls? Eur Respir J. 1997; 10(6):1254-60.

11. Sant'Anna CA, Solé D, Naspitz CK. Short stature in children with respiratory allergy. Pediatr Allergy Immunol. 1996; 7(4):187-92.

12. Priftis KN, Panagiotakos DB, Antonogeorgos G, Papadopoulos M, Charisi M, Lagona E, et al. Factors associated with asthma symptoms in schoolchildren from Greece: the Physical Activity, Nutrition and Allergies in Children Examined in Athens (PANACEA) study. J Asthma. 2007; 44(7):521-7.

13. Khan WH, Mohsenin V, D'Ambrosio CM. Sleep in asthma. Clin Chest Med. 2014; 35(3):483-93

14. Giannini C, Mohn A, Chiarelli F. Growth abnormalities in children with type 1 diabetes, juvenile chronic arthritis, and asthma. Int J Endocrinol. 2014; 2014:265954.

15. Hauache AG, Spinola-Castro A, Lourenzi V, Tufik S, Naspitz CK, Solé D. IGF-I, IGF-BP3, and GH serum levels after stimulation tests in prepubertal allergic boys. J Investig Allergol Clin Immunol. 2003; 13(4):266-71.

16. Bush A. Inhaled corticosteroid and children's growth. Arch Dis Child. 2014; 99(3):191-2.

17. Antonio MA, Ribeiro JD, Toro AA, Piedrabuena AE, Morcillo AM. [Evaluation of the nutritional status of children and adolescents with asthma]. Rev Assoc Med Bras (1992). 2003; 49(4):367-71.

18. Singh SB, Weinberger MM, Zimmerman MB, Starner TD. Growth of preschool age children receiving daily inhaled corticosteroids. Allergy Asthma Proc. 2013; 34(6):511-8.

19. Doull IJ. The effect of asthma and its treatment on growth. Arch Dis Child. 2004; 89(1):60-3.

20. Jentzsch NS, Camargos P, Sarinho ES, Bousquet J. Adherence rate to beclomethasone dipropionate and the level of asthma control. Respir Med. 2012; 106(3):338-43

21. Pruteanu AI, Chauhan BF, Zhang L, Prietsch SO, Ducharme FM. Inhaled corticosteroids in children with persistent asthma: is there a dose response impact on growth? An overview of Cochrane reviews. Paediatr Respir Rev. 2015; 16(1):51-2.

22. Norjavaara E, Gerhardsson De Verdier M, Lindmark B. Reduced height in swedish men with asthma at the age of conscription for military service. J Pediatr. 2000; 137(1):25-9.

23. Allen DB. Inhaled corticosteroids and growth: still an issue after all these years. J Pediatr. 2015; 166(2):463-9.

24. Morishita R, Franco MC, Suano-Souza FI, Solé D, Puccini RF, Strufaldi MW. Body mass index, adipokines and insulin resistance in asthmatic children and adolescents. J Asthma. 2016; 53(5):478-84.

25. Castro-Rodriguez JA, Pedersen S. The role of inhaled corticosteroids in management of asthma in infants and preschoolers. Curr Opin Pulm Med. 2013; 19(1):54-9. 